\title{
Correction to: Accuracy enhancement for monthly evaporation predicting model utilizing evolutionary machine learning methods
}

\author{
S. Mohamadi ${ }^{1}$ (D) M. Ehteram ${ }^{2} \cdot$ A. El-Shafie ${ }^{3}$
}

Published online: 24 June 2020

(C) Islamic Azad University (IAU) 2020

\section{Correction to: \\ International Journal of Environmental Science and \\ Technology (2020) 17:3373-3396 \\ https://doi.org/10.1007/s13762-019-02619-6}

The authors have improved the quality of figures 6 and 7.

This article does not have Acknowledgement and funding.
In the original articles, we have lost these two citations in the below paragraphs.

This ability allows sharks to detect where an odor is originating from and distributed (Abedinia et al. 2016). The shark movement is faster, when the concentration of odor is

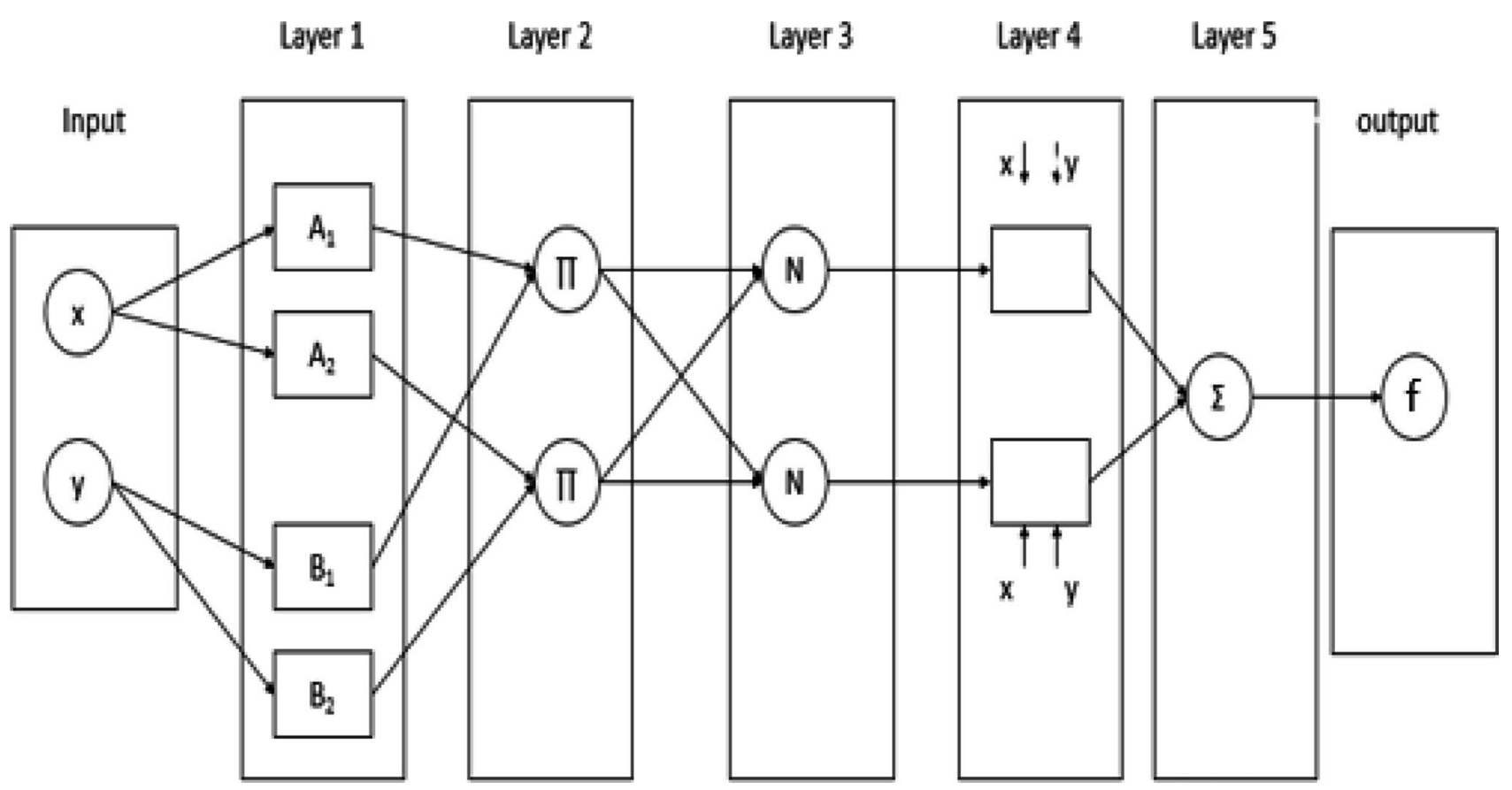

Fig. 6 ANFIS structure model (x, y: input, A and B: the membership function)

The original article can be found online at https://doi.org/10.1007/ s13762-019-02619-6.

S. Mohamadi

mohamadisedigeh@gmail.com

1 Department of Ecology, Institute of Science and High Technology and Environmental Sciences, Graduate University of Advanced Technology, Kerman, Iran
2 Department of Water Engineering and Hydraulic Structures, Faculty of Civil Engineering, Semnan University, Semnan, Iran

3 Civil Engineering Department, Faculty of Engineering, University of Malaya, Kuala Lumpur, Malaysia 
Fig. 7 Flowchart of applied FFA

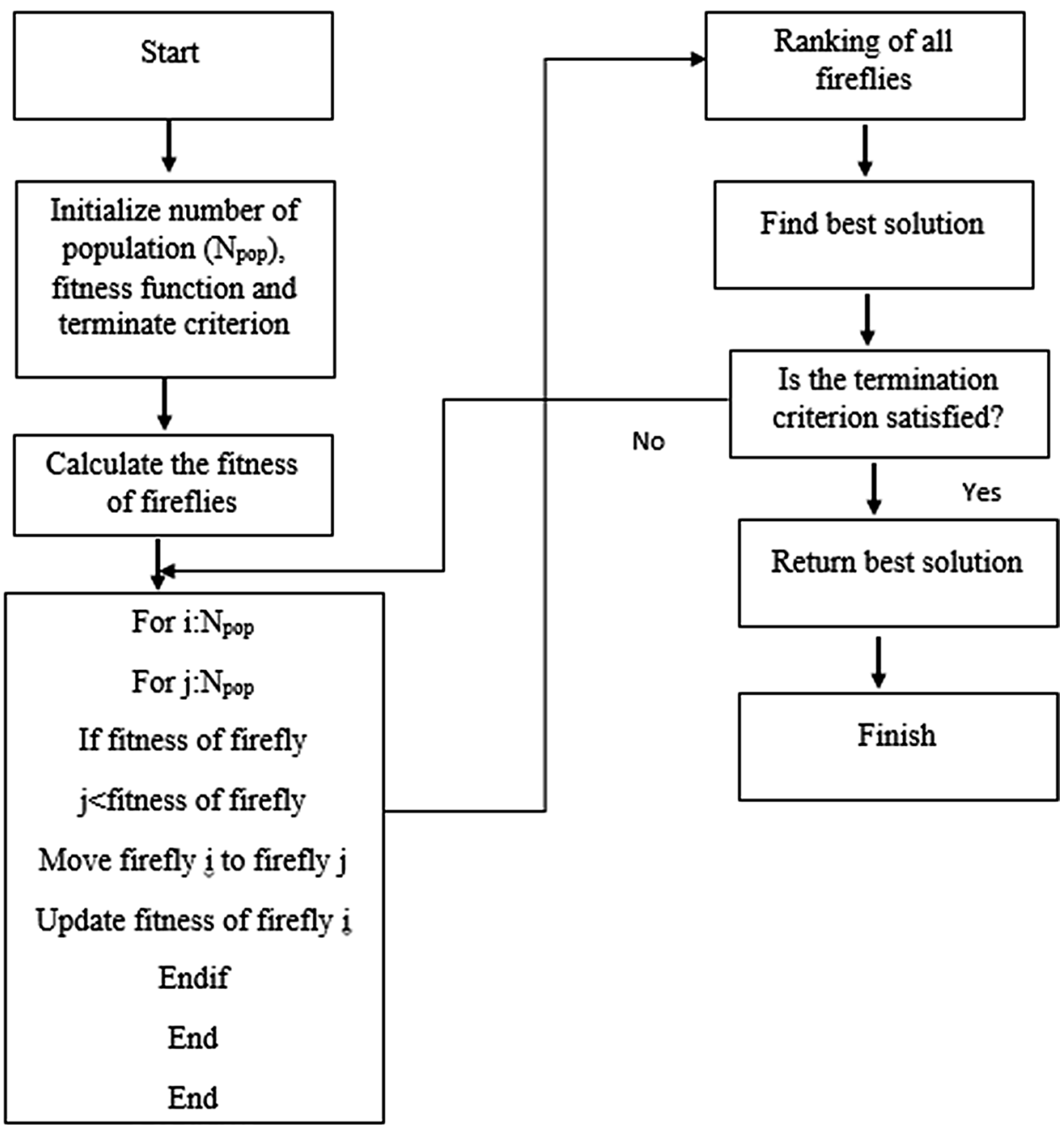

stronger, (Abedinia et al. 2016). The slightest traces of odor in sea can be found out by the sharks (Abedinia et al. 2016).

The indirect method (Penman-Monteith) and direct methods (class U pan and class A pan) as empirical models can be used for predicting evaporation (Allawi and El-Shafie 2016). However, their performance is not accurate because the evaporation process is a nonlinear (Allawi and El-Shafie 2016).

\section{References}

Allawi MF, El-Shafie A (2016) Utilizing RBF-NN and ANFIS methods for multi-lead ahead prediction model of evaporation from the reservoir. Water Resour Manag 30(13):4773-4788

Abedinia O, Amjady N, Ghasemi A (2016) A new metaheuristic algorithm based on shark smell optimization. Complexity 21(5):97-116 